\title{
REVITALIZING RESEARCH IN THE JUNIOR HIGH SCHOOL PROGRAM: INPUTS FOR CURRICULUM DEVELOPMENT AND FACULTY DEVELOPMENT PROGRAM
}

\author{
Gilbert S. Arrieta \\ Don Bosco Technical Institute, Makati City, Philippines \\ Philippine Normal University, Manila, Philippines \\ arrieta.gs@pnu.edu.ph \\ Arlyne C. Marasigan \\ Philippine Normal University, Manila, Pbilippines \\ marasigan.ac@pnu.edu.ph
}

\begin{abstract}
The study aims to find out the experiences and observations of teachers in teaching Research to Junior High School students. In particular, it wants to identify what needs to be enhanced in the research curriculum and faculty development program, particularly in terms of the knowledge and skills of research teachers and the other teachers in the junior high school department. It found out that students consider research a difficult subject that makes them less interested. Research theories and concepts appropriate for junior high school must be identified for curriculum revision. Teachers believed that they need to enhance their knowledge and skills and gain more experience in writing to become creative and confident research teachers. For teachers to be actively engaged in research, they have to be provided with training and workshops related to research and be strongly encouraged to do at least action research. The faculty development program may also include creating research mentors and the provision of opportunities for publication.
\end{abstract}

Keywords : learning and teaching research, research curriculum, research capability, faculty development program

\section{A. INTRODUCTION}

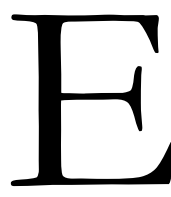
verybody wants their curiosity to be satisfied, and the level of curiosity depends on one's level of interest. The more interested the person, the more effort will be

exerted to satisfy one's curiosity. Driven by curiosity, people seek to explore the world. At no time in life is curiosity more powerful than in early childhood (Perry, 2003). Children ask a lot of questions and they will not stop until they get the most convincing answers.

When a child enters school, he/she becomes more exposed to many things that lead him to identify the most interesting topic. As he gets older, he/she becomes even more fascinated to more serious matters relevant to his/her life. The desire to know more grows stronger and will not settle for any knowledge that is not very convincing and true. 
In school, students' interest in knowing more about a particular subject matter can be guided by engaging them in a more scientific approach. In grade school, they are introduced to investigatory projects, particularly in Science, where they are taught about conducting experiments. Science investigatory projects are testimonies to their learnings and discoveries, particularly when presented in class or fora. As they go up a grade level higher, it is expected that their knowledge and skills in conducting experiments are enhanced through their exposure to more subject matters. In high school, the word "research" becomes a familiar term for teacher8J s requiring students to read and find out more information about an assigned topic. However, when they reach Grade 10, students are introduced to research as a scientific process in their English class. In particular, research as a lesson is found in the fourth quarter of Department of Education K-12 English curriculum guide.

In a private school in Manila, Philippines, Research was evidently integrated in the English curriculum even before the signing into law the "Enhanced Basic Education Act of 2013" or popularly known as K-12 Basic Education Program. Despite the less emphasis on research as a subject matter in the English curriculum, it was spread across all quarters where students are asked to present or defend their research before the end of the school year. In the K-12 program, research continues to be evident in the Grade 10 English curriculum of the school. In school year 2019-2020, the department decided to take a different but a more positive turn by allotting one hour specifically for research. For Grades 7 and 8, research is part of the Science curriculum where it is more focused on conducting science investigatory projects. Grades $9 \& 10$ are embedded in the English curriculum where the research and scientific writing are emphasized. This decision means that research is an independent subject from English.

Incidentally, the school launched its new vision-mission statement in the same school year, which states "A nurturing, responsive, research-oriented, and innovative school for the young", recognizing the importance of research. The direction of the junior high school department on research supports the school's vision and commits to establishing a Research culture. However, there are many challenges in realizing the school's vision, particularly the contribution of the department on research. Having research as a subject is just the initial step in taking the course towards becoming a research-oriented institution. Research has to be introduced to students as early as junior high school.

Making research a new subject apart from English may be perceived by students as an added burden considering they have more subjects than other junior high school students. Aside from the usual academic subjects, four more technical subjects have to study since the 
school follows a dual curriculum program (academic and technical). The nature of research as subject may also be deemed by students as difficult because it entails a lot of reading and work.

After a year of revitalizing research in the junior high school curriculum, it is imperative to find out experiences and observations of academic heads and research teachers in teaching research as a separate subject. This study also aims to know what needs to be improved in the curriculum and interventions for faculty development leading to the school's vision of becoming a research-oriented school. Through an enhanced curriculum and faculty development program, the knowledge and skills of teachers and students will be enriched, producing better research outputs.

The following are the research questions for this study: (1)What are the observations and experiences of academic heads and teachers in teaching research as a subject? (2)What should be enhanced in the research curriculum to develop the knowledge and skills of students? (3)Based on the findings, what inputs can be included in the faculty development program to enhance teachers' research knowledge and skills?

\section{B. LITERATURE REVIEW}

\section{Engaging Students in Research}

Whenever a new subject is introduced to students, they ask about its relevance in their present and future lives. In the case of research as a subject, its significance is very clear. Generations of students have asked for relevance in their studies: "Why do I need to learn this? When will I use it?" Research offers students a concrete demonstration of the principles and concepts covered in textbooks and lab sections. The active learning element of research allows students to connect to their interests that may not ordinarily be made in passive learning environments. Research experience has been credited with improving students' motivation for learning. Students can pursue their individual interests. Intellectual curiosity is sparked, and research provides undergraduates with an opportunity to take greater ownership of their own learning process (Erickson, 2001).

Despite the value of research, students perceived it as a difficult subject for it entails a lot of work and analysis. As a subject, the theories and processes are scientific and challenging, making students truly engaged in learning. "Research" is a feared subject among most senior high school students. On the contrary, this is not the case for senior high school students of Pampanga High School. They have been trained to think of and use their research subject as 
an important component of creative and critical thinking, and as a requirement of genuine academic excellence. In training the student-researchers with the right approach to qualitative research, the research subject enabled students to relate, connect and reflect on their own stories. Student researchers talked about how their chosen topic inspired them to study the subject objectively and closely (Bondoc, 2019).

Students exposed to research at an early age will be better prepared to understand and scrutinise information, especially as technology continues to thrive and affect our lives. In today's time age where misinformation and "fake news" spreads like wildfire, we must learn to think critically and to distinguish between trustworthy and not-so-trustworthy information. Understanding how research works (e.g. correlation doesn't equal causation, study limitations, etc.) will allow you to see through the sensationalist headlines and make better decisions in literally everything (e.g. personal finances, studying, etc.). Building and flexing that critical thinking muscle can be invaluable at all levels of your academic journey and being exposed to Research help facilitate that (Diza \& Belgrave, 2019).

Another research study pointed out that school literacy is often narrow, and the writing events students take part in during lessons in school science often have little relevance for practices outside of school. Allowing students to act as researchers and confront the struggles of the research process provides them with valuable experience of varied literacy practices and approximates how adult scientists work. Through careful facilitation of the research process by the teacher, the students in our study have taken part in the scientific text culture, using texts and writing for purposes beyond those traditionally associated with school science. While the research process these students undertook did not result in any new scientifically valid knowledge about dog's olfaction, we see evidence that the literacy practices they engaged in were considered meaningful in the here-and-now situation. In addition, the students experienced these ways of writing as more authentic and relevant for their future as professional adults. In our fast-changing world, learning to ask questions, gather information, and present findings and ideas will always be relevant, and students should experience these ways of acting in the world of texts as early as possible (Bjørkvold \& Blikstad-Balas, 2018).

Doing research work in Science provides an opportunity for students to develop their research skills. Studies show that students—and the general public as a whole-have a narrow view of what a scientist is, does, and looks like. The opportunity to work in a research group may be the first time that high school students encounter a "real scientist." Likely, it is also their first chance to peek inside the black box that is scientific research—something they may only know from the media. They will experience firsthand what it is like to work in a research 
environment (whether they are doing experiments or computational work) and will likely be surprised by how communication and collaboration not only are necessary to the scientific process but also make research more rewarding. Performing scientific research gives students the opportunity to witness the practical applications of concepts they have been taught in school and to observe how the experimental and analytical work done in research settings builds upon what they have learned in the classroom. Importantly, they will also experience the excitement and challenges of investigating open-ended questions without predetermined answers. Authentic research experiences can empower students to pursue research opportunities as undergraduates and to consider careers in science, technology, engineering, and mathematics (Lescak, O’Neill, Collu, \& Das, 2019).

In another study, the benefits of research to students are big. The results showed that, in general, students who took the subject had more positive attitudes towards doing research and design activities than regular students. Both student groups appeared to find doing research activities more relevant than doing design activities. The results of this study provide useful information for teachers as well as teacher educators about the existing attitudes of students, for example their preference for design projects over research projects (Vossen, Henze, Rippe, Van Driel \& De Vries, 2018).

Though research appears to be a difficult subject, high school and college students will find it interesting given the correct perception and orientation. Likewise, with capable teachers and a clearly spelled out research curricula will enable the students to develop their research knowledge and skills.

\section{Engaging Teachers in Research}

Like the students, teachers are not immediately drawn in doing research because they know that it demands a lot of time and effort. Considering their workload, they have to squeeze in their schedule a research work to make it happen. Their college experience in research may have given them a real taste of how to do it, and it is not easy. However, research showed that teachers themselves do not always consider classroom-based research with teachers to be an attractive or meaningful model for professional development. This is due to the notion that teachers may be hesitant to engage in research, because of reasons that include a lack of time, weak motivation, a sense that it is a low priority and the belief that research results are irrelevant to the immediate needs of the teaching and learning situation (Gutierez \& Kim, 2017).

Despite the challenges in doing research, they recognize its value because it will improve their performance as teachers. The objective in academic research is to produce new 
knowledge but for most teachers doing research, the purpose is to improve practice while being informed by theory at the same time. When they do literature review, they don't have to be exhaustive. The purpose is to look for literature that pertains specifically to the classroom teaching strategy that they wish to try or explore. Teachers don't have to feel intimidated by the prospect of venturing into research. There are different levels of complexity, and it is advised that teachers have to start small. Starting small is important. You do something manageable and within your limits, whether in your sample size or the research method and design you choose. If you're comfortable with qualitative, you do qualitative. If you're comfortable with quantitative, do quantitative. However, teacher research need not be less rigorous or objective than that of the academic variety. It is advised that teachers follow the steps of doing research (e.g., setting the research problem, exploring the literature, establishing the research question) as closely as possible. As long as every step is done systematically, your research would have met the criterion of rigor (Salleh, 2014).

Over and above how to start doing research, a study revealed that teachers, through collaboration, sustainability, trust, and commitment, recognized the advantages of classroombased research in improving their instructional capacities. The analysis of the teacher reflections yielded three major themes that are significant in the consideration of classroombased research: increased understanding of classroom dynamics, shared ownership and involvement, and reflective practice to connect and resolve ideas against prior beliefs. With the full involvement of the teachers, it appeared that the classroom research-based employed helped to empower teachers and assisted in eliminating negative notions of research. Instead, the professional development became an opportunity for immediate learning (Gutierez \& Kim, 2017).

In the Philippines, the Department of Education strongly supports Research through Basic Education Reform Agenda. As clearly stated in the order, the Department sustains its progressive orientation by ensuring that its actions are informed by sound and relevant evidence from research. Evaluation research can draw lessons from past and existing education programs and identify ways to improve them. Policy studies can define problems and generate possible solutions. Social experiments can compare school interventions' effects and weed out ineffective from promising ones (DepEd Order no. 39 s. 2016).

While teachers are asked to research as part of their requirements and promotion, teachers still have to do it for professional development. In a study with public high school English teachers in Mindanao, Philippines as participants, the findings suggest that teachers' motivations to do research were more personal rather than professional, teachers recognized 
some benefits of doing school and classroom-based research for their teaching practices and career development. Challenges that were reported include the lack of financial support, heavy teaching load, lack of research skills and knowledge, and lack of research materials and resources (Ulla, 2018).

Engaging teachers to be better researchers, especially those teaching research, will need a stronger push and motivation from school leaders.

\section{Building Capacity for Teachers as Researchers}

If the school wants the students to become researchers, it must start with teachers. As the saying goes "You cannot give what you do not have.", teachers cannot inspire students to learn how to do research if their research capability is not strong. This is not only about research teachers but also all teachers in the department.

The idea of teachers doing research will only be sustainable if teachers themselves want to embark on it. Here, the school leadership plays a very important role in enabling them to do so. It is advised that school leaders build capacity through appropriate professional development. Instead of action research workshops that last only a couple of days, teachers may benefit more from having an external consultant or teachers with experience in teacher research to guide them along every step of the research process. In this way, they can get "just-in-time" help when they need it, be it in reviewing the literature or choosing a suitable research design for their research project (Salleh, 2014).

Various studies revealed that professional development for teachers should include strengthening their research knowledge and skills. A study showed a need for intensive seminar/ training write-shop for technical writing of completed research. They need to be highly capable of writing complete research that can be presented and published. The researchers also recommended the action plan for the seminar/training write-shop activities, timeframe, expected output, material requirements, and the responsible entity/person (Tamban \& Maningas, 2020). In another study, it yielded similar results. It concluded that the challenge of encouraging teachers lies in building the capacity on the basics of research writing. Their current research skills need enhancement in the form of sustainable research pieces of training and programs. Moreover, it pointed out that more than highlighting support programs for the actual research writing, it is imperative that teachers be equipped with the needed competencies first to conduct research. A research culture will be improved, starting with technically-equipped teachers who possess the know-how of research writing (Ancho, Diaz-Cruz \& Calimbahin, 2019). 


\section{RESEARCH METHOD}

This study employed a qualitative method using the phenomenological study. It is an approach to qualitative research that focuses on the commonality of a lived experiences within a particular group. The fundamental goal of the approach is to arrive at a description of the nature of the particular phenomenon (Creswell, 2014). There were seven participants in this study that included three academic heads and four research teachers. They have been teaching English and Research in the last three years in the Junior High School Department in a private school in Manila, Philippines. Being English teachers, they have seen and experienced supervising and teaching research before and after it became a separate subject from English.

Experts validated the interview questions in English Teaching, curriculum and instruction, and educational management. The following questions were asked : (1) Based on your observations and experiences, what are the initial impressions of JHS students on research as a subject? (2) Based on your experience, what do students find difficult and challenging in research as a subject? (3) As a research teacher, what do you consider a challenge in teaching Research to JHS students? (4) What specific topics or skills should be emphasized in the research curriculum? (5) What knowledge and skills in research should JHS research teachers enhance? (6) What interventions, training and opportunities should be provided to JHS teachers to enhance their research knowledge and skills?

To analyze the data, coding was used. In coding, the researcher organizes data collected into segments and assigns a word or phrase to them as labels (Creswell, 2014). Themes were identified after analyzing the data.

In terms of ethical issues, permission was sought from the principal, and participation was voluntary. Their participation in this study will not affect the status of the participants in the school. No names were mentioned in the study, including the school where this study was conducted.

\section{RESULTS AND DISCUSSION}

Introducing research as a separate or new subject last school year is a welcome initiative by the junior high school department to engage both teachers and students in conducting research. It indicates the seriousness of the department as well as the institution in becoming a research-oriented school. The discussions that follow are based on the research questions to provide a springboard to take research to the next level. 
1. What are the observations and experiences of learning area heads and teachers in teaching research as a subject?

Teaching research will always be challenging particularly to junior high school students. As a stereotyped subject, research appears to be a less interesting subject for it suggests more work and requirements. Based on the experiences and observations of the teachers, the students' initial impressions are difficult, time consuming, and intimidating. A participant said that :

\section{"I think they always feel intimidated and pressured in the beginning. Probably because they know that it's a new subject that they don't have any background idea about."}

Being a new subject, students appeared to be interested in the subject despite having no background about it but only some show interest to it. Most of them see it as an added burden or hassle to their current load of subjects. They didn't have any idea what it really is and how it will be done. Another participant shared that :

"Students initially thought that research is an interesting and easy subject, but as they started doing the research tasks, they started to realize that research work was not as easy as they thought, especially when they were tasked to revise their work several times."

Talking about the difficulty and challenges in research encountered by the students, they find research writing itself as the most difficult. In particular, literature review writing, data analysis, data gathering, and identification of research topic. A participant mentioned that :

"As far as I know, they find it difficult to think of a topic for research and look for references. Also, they said that analyzing related studies was also hard for them to do."

The nature of the subject is already difficult. Because of it, students are not drawn to research immediately. A participant intimated that :

"The very concept of conducting research is already hard to grasp. What makes it so difficult is the complexity. Some lessons are just too advance for them. Without actual field work, they couldn't really comprehend the subject."

When classes were held online beginning Term 3 of school year 2019-2020, the students also found it difficult to understand the lesson. A participant shared that :

"Particularly in this online class, the students really find it difficult to absorb 
the lessons. There are a lot of terms, concepts, and ideas that they need to really understand so they can work on their own. The consultation hours are not enough

to answer their queries. Aside from doing exactly the task, they also still need to

understand the subject itself making it more difficult."

Based on the observations and experiences of teachers after more than a year of teaching research as a subject, the students find research as a challenging and difficult subject. The theories and concepts are new which are not easy to understand.

In terms of the challenges encountered by the teachers in teaching research, the nature of the subject, lack of exposure to the subject itself, insufficient time allotment for the subject, and how to make the students understand and do research are the difficulties they experienced. A participant honestly admitted that :

"It's also a very boring subject to teach. This, in a way, affects the way they (students) feel about it."

Considered as a technical and serious subject with a little room for fun, teacher's creativity is often tested. Presenting and discussing the key theories and concepts of research, particularly junior high school students, poses an unlikely challenge to every teacher. They always think of the easiest and most creative way to teach the subject where they will understand them. A study on teaching research revealed that the shift toward studentcenteredness through the use of interactive small group activities based on primary resources appears to have significantly enhanced students' learning in this case. The classroom experience was characterized by a high level of dialogue and interaction, the assessment results suggest overall strong engagement with the subject matter, and student feedback was very positive. One of the key strengths of this approach was that it allowed students to build common experiential ground, which provided a shared base for engaging with more technical aspects of the subject matter. This is increasingly important in higher education contexts where flexible learning pathways are producing diverse student cohorts with no, or highly limited, common learning experiences (Barraket, 2005).

However, the teacher's preparation and lack of exposure are factors in this concern. Qualified teachers may be able to present and teach research theories in a way students will understand them. A participant clearly indicated that :

"I do not consider myself to be a research teacher. As an English teacher, who was assigned to teach research, I think the challenge starts with the teacher himself/ herself. Actual, qualified research teachers are the ones who'll know how to approach the subject. Maybe then it wouldn't be as difficult for the students." 
A teacher who has not undergone the rigorous process of research may have a hard time teaching research because the subject implies not only theory but also practice. No concrete and credible experiences can be shared by a research teacher who has not conducted and written an action research at least. A truly qualified research teacher must have at least published a research or earned a master's degree in education. Being an English teacher does not immediately qualify as a research teacher.

Research as a separate subject has revealed some serious challenges. The teachers' issues and concerns based on their experience have to be addressed to justify that the subject must be apart from English in the Junior High School curricular program.

2. What should be enhanced in the research curriculum to develop the knowledge and skills of students?

The research curriculum often includes the definition, literature review, parts of research, and methods. Activities may include identifying the research gap, writing the introduction, and defending the proposal. At the end of the school year, it is ideal to have the research defended by the students.

Based on the teachers' experiences, the students' knowledge and skills that need to be developed are writing, research problem identification, data gathering, and analysis. Out of seven participants, three teachers pointed out the need to revise the research curriculum particularly on research theories and concepts. The performance tasks or activities should be doable or according to the level of the students. It seems that the focus is more on the theories and less on practice. Supporting the importance of practice is a study that found out the format of "learning by doing" was very rewarding for the students. This process used a hands-on approach to learning empirical research methods. Students got their hands dirty, both students and the instructor became frustrated, and students learned about the constraints that bind the research process. Understanding empiricism and the systematic analysis of data was an important lesson conveyed to the students in this class, because they saw how this step creates the basis of good social-science research. Students found that the research process allows for some creativity by the researcher, and that there is a clear line between being creative and being dishonest. They learned that the research process puts a premium on transparency and transmissibility, meaning that readers of research reports should be able to duplicate the findings (Aguado, 2009). 
Teachers found out that the limited time for research prevent students from developing their knowledge and skills. Apart from this, junior high school students have to take that prevent them from giving their $100 \%$ in research writing. Having more subjects means more requirements. In a study, teachers noted that students acquired some research skills and gained the experience of doing research. However, the teachers find it too demanding and taxing on the students' time (Meerah \& Arsad, 2010).

A participant pointed out that the identification of a research problem or gap is the triggering point to make students interested in research. Before any research theories or concepts are discussed, a practical approach is necessary to initiate the development of research knowledge and skills. Students have to ask a question based on their interest. Research is question driven. It is based on a topic whose soundness is measured by a scientific criterion of validity. It is considered good if it is premised on a possibility of generating knowledge that can improve the quality of human life, quality of social order, and the integrity of the environment (Sampa, 2012). One of the critical steps that students will take in research writing is the choice of a problem. A great number find this stage stimulating if not challenging. Often, this is one factor that hinders students in pursuing Research (Sevilla et al, 2003).

The development of research knowledge and skills of students is important and training should start at elementary level. It will prepare them better for senior high school, college, and graduate studies. Suppose the students have research experience at various educational levels before advancing to graduate studies. In that case, they will acquire the skills of observation, manipulation, coordination and internalizing the research attitude, the habit of inquiry or problem solving and all the features of a good researcher besides possessing the knowledge of the skills of conducting research, the methods and materials needed to solve the problem, the collection of empirical data or observations, the analysis of data and drawing on of their findings to share with others Thus, various intervention and strategies, formal and informal, have been tried to inculcate research culture among future citizens (Meerah \& Arsad, 2010).

3. Based on the findings, what inputs can be included in the faculty development program that will enhance teachers' research knowledge and skills?

Learning is a continuous process. Teachers never end learning because education is dynamic. They have to keep up with the new developments that will shape teaching and learning and teachers. For this reason, each school has an in-service training faculty development program. With the school wanting to become a research-oriented community, it is imperative to develop the research capability of all teachers through various pieces of 
training and opportunities. It must be included in the faculty development program of the school.

Climbing the ladder of research culture in the Basic Education Institution in the Philippines requires collaboration and effort from both the teachers and the institution. Such an effort must be focused on the driving forces that would help teachers improve their research capabilities such as attitude towards research, research knowledge and a supportive institution. This study, therefore, provides an implication that there is a need for the Department of Education to develop a comprehensive research capability enhancement program to help the master teachers raise their level of capability. Such program may include a series of training focusing not only on increasing the teachers' knowledge in research but also on conducting, presenting, and publishing their research output (Wong, 2019).

All participants suggested that all teachers be provided with regular training-workshops on research. For research teachers, the training should focus on pedagogy, writing, and publication. A participant said that a teacher must also be a researcher by practicing it. $\mathrm{He} /$ She pointed out that :

"Aside from the trainings, seminars on research, teachers should also bave the experience in conducting actual research."

A good start for research to become part of the school's culture is to do action research. Teachers cannot be also called researchers unless he/she has conducted an action research. The best output for any regular trainings and workshops related to research is an action research. Doing research enhances the performance of teachers in classroom work and curriculum development. Teachers' capability to respond to new ideas with continuing improvement in their teacher professional knowledge is strengthened by being inquisitive, questioning their practices and the influences on students' experiences of learning, as well as understanding the importance of reading research literature. Unlike routine teacher reflective practice or even the reflective processes within a Teaching as Inquiry cycle for change, when teacher research occurs, it is more purposefully planned. The research question(s) provides an opportunity for the teacher to ethically and systematically (through research design) gather appropriate evidence to examine an issue within the context of what is already known in the research literature and write about it for a wider audience. Research is a form of reflective practice that goes beyond simply individual inquiry and makes the process and its outcomes public (Mills \& Earl Rinehart, 2019). 
It is also suggested that an opportunity for publication be provided to teachers who have already advanced knowledge and skills in research. What can be included in the faculty development program is the creation of research mentors' group who will guide teachers in writing their research. This will be a strong support to teachers who aspire to become researchers and earn master's degree. A participant suggested that :

\section{"Attending trainings and seminars is not enough. Teachers must be assisted by mentors who have experiences and exposure to research. The school must assist the teachers in research publication."}

Ironically, in a study on mentoring teachers on research, it found out that the continuing developmental process of learning mentoring, specifically regarding supporting teacher research, has received relatively little attention in English language teaching. It explores how three teacher-research-mentors, experienced classroom practitioners but novices in researchmentoring, grew into their new role while supporting teacher research projects in different English language higher education contexts in Turkey over one year. Vignettes reveal that they became conscious of needing to provide psychological support to sustain teacher-researchers motivation from starting their research projects to completing them successfully, presenting findings and writing them up, and developing in other roles as subject-specialists sharing knowledge about research to a lesser extent. Outcomes, in terms of the quality of research produced by the teacher-researchers in their contexts, appeared influenced by the different characteristics of their institutions and the degree of external support in the form of mentormentoring the teacher-research-mentors could access. Given the increasing interest around the world in teacher research as an empowering form of professional development, there is a growing need for teacher-research-mentors. These findings shed light on research-mentors' developmental needs might be of interest to teacher educators (Dikilitaş \& Wyatt, 2018).

Most especially those involved in teaching research admitted that they need to develop their knowledge about research particularly effective strategies and techniques. They need the experience in doing a complete research. Conducting and writing a research paper are considered the skills training for teachers after learning the different research theories and concepts. The inclusion of research publication in the faculty development program will enable the all teachers particularly research teachers to conduct research and become credible and confident. If a research teacher has no experience in doing research, he/she will just be teaching the junior high school students research theories and concepts which are not grounded on one's experience. Doing research may not be easy but can be done. In fact, a 
study revealed that teachers were slightly capable of conducting research and having neutral attitudes toward it, motivated to write research, had a high level of difficulties in research processes, and moderately capable of action planning. They also show evidence of potential in mentoring. Further, mentoring and action planning skills, motivation to write research, attitudes toward research, and the number of studies completed by teachers correlate with their research capability at different magnitudes of the relationship. Notably, the research capability of teachers had a low, negative but significant relationship with their age and accumulated years of service. Thus, this capability deteriorates as they age and accumulate years of service. The motivation to write research, the number of studies completed, and age were the determinants of research capability. It was concluded that research capability can be determined and predicted by how motivated teachers are to write research, how productive they are in research, and how young they are when they engage in this rigorous endeavor. The study identified and recommended topics for continuing professional development (Caingcoy, 2020).

A faculty development program with a clear provision for building research capability for teachers will lead to a better research curriculum development for junior high school students, and more qualified and confident teachers teaching and conducting research.

\section{E. CONCLUSION}

Revitalizing research in junior high school particularly making it an independent subject is a timely initiative and response to the school's vision. Becoming a research-oriented community means continuously engaging in academic and scholarly developments to enhance teaching and learning. As the institution begins the pursuit of its vision related to research, this study found out issues and challenges, including inputs that can be used to revise the curriculum and enhance the faculty development program. Based on the findings, it can be concluded that junior high school students find research difficult and less interesting subject. Basic research knowledge and skills of students cannot be developed unless the basic research theories and concepts

Most research teachers also find it difficult to teach because they did not have the necessary training and qualifications. They need to acquire more knowledge and skills before they can confidently teach research. To make the research more interesting and stimulating, it is necessary to review the curriculum and identify research concepts and theories appropriate for junior high school. Research is important for teachers, but they cannot confidently do it 
due to lack of opportunities, training, and experiences in conducting and writing research. The faculty development program should include regular training, publication opportunities, and mentoring in order to establish a research culture leading to the realization of the school's vision-mission. If faculty members particularly the research professors have the knowledge, skills, and experience, it can be assumed that the teaching of research will become more creative, responsive, and output-driven.

\section{REFERENCES}

Alexander Aguado (2009). Teaching Research Methods: Learning by Doing, Journal of Public Affairs Education, 15:2, 251-260, DOI: 10.1080/15236803.2009.12001557

Ancho, Esperanza Diaz - Cruz, and Calimbahin (2019). Exploring Teachers' Research Competency: Inputs to Policy Enhancement. ETERNAL (English, Teaching, Learning, and Research Journal), 5(2), 203. doi:10.24252/eternal.v52.2019.a2

Barraket, J., Teaching Research Method Using a Student-Centred Approach? Critical Reflections on Practice, Journal of University Teaching \& Learning Practice, 2(2), 2005. http://ro.uow.edu.au/jutlp/vol2/iss2/3

Bjørkvold, T., \& Blikstad-Balas, M. (2018). Students as researchers: What and why seventh-grade students choose to write when investigating their own research question. Science education, 102(2), 304-341 https://doi.org/10.1002/sce.21324

Bondoc, A. G. (2019). Embracing the culture of research in senior high. The Manila Times. April 11, 2019 https://www.manilatimes.net/2019/04/11/campus-press/embracingthe-culture-of-research-in-senior-high/538362/

Caingcoy, Manuel, Research Capability of Teachers: Its Correlates, Determinants and Implication for Continuing Professional Development (June 20, 2020). http://dx.doi.org/10.2139/ssrn.3631867

Department of Education. Adoption of the Basic Education Research Agenda. DepED Order No. 39 s. 2016.

Diaz, C. and Belgrave, S. (2019). American Psychological Association. Psych Learning Curve. http://psychlearningcurve.org/early-research-experiences-why-students-should-seek-outopportunities-as-early-as-highchool/\#: : text $=$ By $\% 20$ engaging $\% 20$ in $\% 20$ research $\% 2 \mathrm{C} \% 20$ you,your $\% 20$ experience $\%$ 20 in $\% 20$ that $\% 20$ environment

Erickson, R. A., "WHY INVOLVE STUDENTS IN RESEARCH?" (2001). Innovations in Undergraduate

Research and Honors Education: Proceedings of the Second Schreyer National Conference 2001. 10. https://digitalcommons.unl.edu/nchcschreyer2/10 
Kenan Dikilitaş \& Mark Wyatt (2018) Learning teacher-research-mentoring: stories from Turkey, Teacher Development, 22:4, 537-553, DOI: 10.1080/13664530.2017.1403369

Lescak EA, O’Neill KM, Collu GM, Das S (2019) Ten simple rules for providing a meaningful research experience to high school students. PLoS Comput Biol 15(4): e1006920. https://doi.org/10.1371/journal.pcbi.1006920

Meerah, T. S. M., \& Arsad, N. M. (2010). Developing research skills at secondary school. Procedia-Social and Behavioral Sciences, 9, 512-516.

Mills, J. P., \& Earl Rinehart, (Suzanne) K. (2019). Teachers as researchers. Teachers and Curriculum, 19(1), 1-5. https://doi.org/10.15663/tandc.v19i1.338

Perry, B. D. (2003). Why Young Children Are Curious. Early Childhood Today, 17(4), 26-27. https://www.scholastic.com/teachers/articles/teaching-content/why-young- ildrenare-curious/

Sally B. Gutierez \& Heui-Baik Kim (2017) Becoming teacher-researchers: teachers' reflections on collaborative professional development, Educational Research, 59:4, 444-459, DOI: 10.1080/00131881.2017.1347051

Sampa, E. (2012). Steps in College Research Writing. Mandaluyong City: Books Atbp. Publishing Corp.

Sevilla et al. (2003). Research Methods. Quezon City: Rex Book Store, Inc.

T.E. Vossen, I. Henze, R.C.A. Rippe, J.H. Van Driel \& M.J. De Vries (2018) Attitudes of secondary school students towards doing research and design activities, International Journal of Science Education, 40:13, 1629-1652. DOI: 10.1080/09500693.2018.1494395

Ulla, M. B. (2018). Benefits and challenges of doing Research: Experiences from Philippine public school teachers. Issues in Educational Research, 28(3), 797-810.

Tamban, V. E., \& Maningas, O. B. (2020). RESEARCH CAPABILITY OF PUBLIC SCHOOL TEACHERS: A BASIS FOR RESEARCH CAPABILITY ENHANCEMENT PROGRAM. PEOPLE: International Journal of Social Sciences, 6(1). doi.org/10.20319/pijss.2020.61.222235

Wong, A. M. (2019). Driving Forces of Master Teachers' Research Capability: Towards Building a Research Culture in the Division Of Romblon, Philippines. International Journal of Advanced Research and Publications, 3(7), 92-97. 